\title{
Experimental study on heat transfer performance of gas-liquid pulsating heat pipe heat exchanger
}

\author{
Fumin Shang ${ }^{1, *}$, Chaoyue Liu ${ }^{1}$, Qingjing Yang ${ }^{1}$, Yifang Dong, Weijia Cao, and Jianhong Liu ${ }^{1}$ \\ ${ }^{1}$ Changchun Institute of Technology, Changchun, China
}

\begin{abstract}
With the continuous development of industrial technology, the safety and efficiency of thermal equipment work in related industries and industrial fields are facing many problems. First, with the improvement of integrated level, the size of electronic components is getting smaller and smaller, and the heat load per unit area is increasing, which makes the traditional heat dissipation method difficult to meet the requirements; second, with the increase of energy-saving pressure, the temperature difference of lowtemperature waste heat recovery is reduced, and the traditional heat exchange equipment is difficult to meet the working requirements. The pulsating heat pipe has the characteristics of small volume and excellent heat transfer performance. In view of the heat transfer performance of the pulsating heat pipe, we designed the gas-liquid pulsating heat pipe heat exchanger and studied its heat transfer performance, which has been verified to be effective.
\end{abstract}

\section{Introduction}

With the rapid and sustainable development of China's economy, the demand for energy is increasing, so it is necessary to carry out energy conservation and consumption reduction. Due to the limitation of working environment and heat exchange efficiency, traditional heat exchanger has been difficult to play a better role in low-temperature waste heat recovery and energy saving in industry. Therefore, a heat pipe heat exchanger accompanied by phase change heat transfer process has emerged.

A pulsating heat pipe (PHP) is a new type of heat pipe invented by Japanese scholar Akachi et $\left.\mathrm{a}^{[1} \sim 4\right]$ in 1994, it has the advantages of geometrical simplicity, free bending, etc. The traditional heat pipe does not have these characteristics, so the pulsating heat pipe has a broad application prospect in the cooling of high-power electronic devices and equipment.

\section{Experiments}

\subsection{Structural parameters of gas-liquid pulsating heat pipe heat exchanger}

The gas-liquid pulsating heat pipe heat exchanger is mainly composed of 20 model U copper tubes with fins passing through the orifice plate and welded into closed circuit with copper elbow and connecting sleeve. Among them, an elbow is a tee structure, and the separate branch pipe is the liquid filling port, which is used for external connection liquid filling system. The tube of pulsating heat pipe is copper. The wall thickness of a single " $U$ " fin pipe is $1 \mathrm{~mm}$, the pipe diameter is $5 \mathrm{~mm}$, the total length is $330 \mathrm{~mm}$, and the center distance between two single pipes is $30 \mathrm{~mm}$. In order to enhance the heat transfer performance of the gas side of the pulsating heat pipe heat exchanger, thin aluminum fins are arranged in the condenser section. The thickness of the single fin is $0.5 \mathrm{~mm}$, the width is $28 \mathrm{~mm}$, and the length is $56 \mathrm{~mm}$. The structure diagram of gas-liquid pulsating heat pipe heat exchanger is shown in Fig.1.
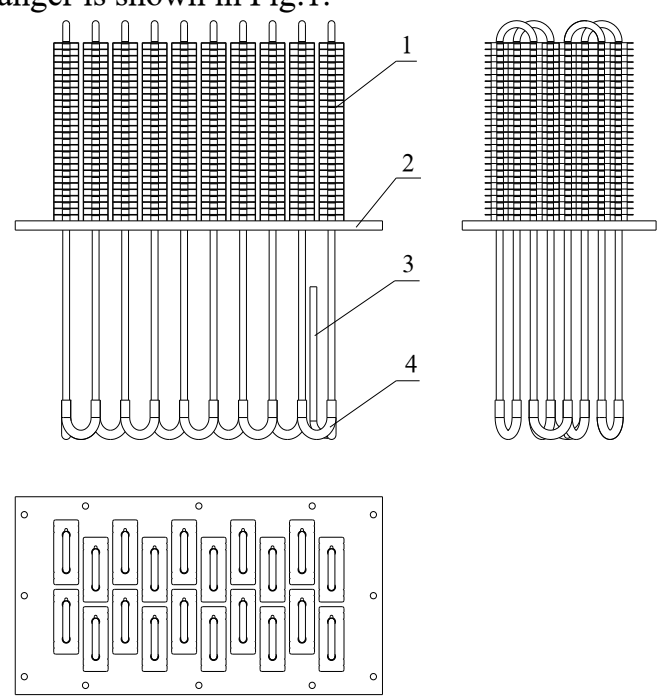

1-fin; 2-clapboard; 3-liquid filling port; 4-connecting elbow

Fig.1.Structure of gas-liquid pulsating heat pipe heat exchanger

"Corresponding author: shangfumin68@163.com 


\subsection{Experimental setup and method}

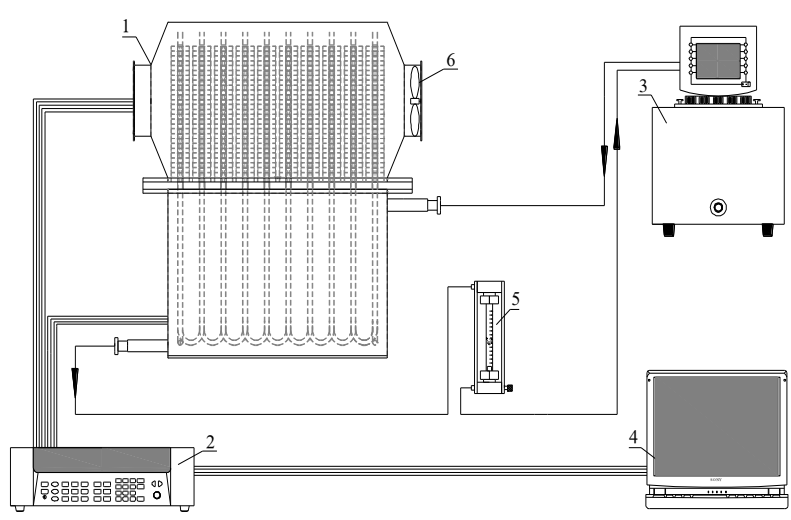

1-experimental setup of gas-liquid pulsating heat pipe heat exchanger; 2-data acquisition unit; 3-thermostatic waterbath; 4-computer; 5-flow controller; 6-Fan

Fig. 2. Experimental setup of gas-liquid pulsating heat pipe heat exchanger

As shown in Fig.2, the experimental setup consists of thermostatic waterbath, flow controller, gas-liquid pulsating heat pipe heat exchanger, data acquisition unit and computer. The experiment collects the experimental data through the data acquisition unit, and monitors the temperature change of each wall temperature monitoring point of the heat exchanger under different heating temperatures through Agilent software, and draws a more intuitive function curve through Origin software to analyze the temperature and oscillation of each monitoring point. Finally, the heat transfer performance of the gas-liquid pulsating heat pipe heat exchanger is determined by calculating the heat transfer $Q$ and the equivalent heat conductivity $\lambda_{d}$.

The experimental heating system is controlled by a thermostatic waterbath. The temperature is $30^{\circ} \mathrm{C}, 40^{\circ} \mathrm{C}$, $50^{\circ} \mathrm{C}, 60^{\circ} \mathrm{C}, 70^{\circ} \mathrm{C}$ and $80^{\circ} \mathrm{C}$, respectively. A flow controller is arranged at the inlet and outlet of the thermostatic waterbath to ensure the flow balance of the inlet and outlet water. The cooling system is composed of heat exchanger gas channel and fan. In the experiment, the fan adopts fixed speed operation mode to provide power for gas flow. Eight type $\mathrm{K}$ thermocouples were arranged in the experiment. Among them, four thermocouples are arranged on the outer wall of the pulsating heat pipe heat exchanger tube to monitor the temperature change of the heating and the condenser sections of the pulsating heat pipe in real time; two thermocouples are arranged on the water inlet and the water outlet side to measure the water inlet and the water outlet temperature in real time; the other two thermocouples are arranged on the wind inlet and the wind outlet side to measure the wind temperature at the inlet and the outlet in real time. When the experimental system is running, the signals received and output by the thermocouple are transmitted to the computer through the data collector for analysis and processing.

\section{Results and discussion}

With the increase of the temperature of the heat source, the temperature difference between the evaporator and the condenser sections of the pulsating heat pipe decreases gradually and tends to be stable. When the temperature difference between the inlet and outlet wind or between the inlet and outlet water of the experimental device tends to be stable, it can be considered that the pulsating heat pipe is in a stable state under the heating temperature. Among them, No.5 and No.6 thermocouples measure the wall temperature of heating and condensation sections of one pulsating heat pipe in the heat exchanger.

\subsection{Wall temperature analysis of pulsating heat pipe}

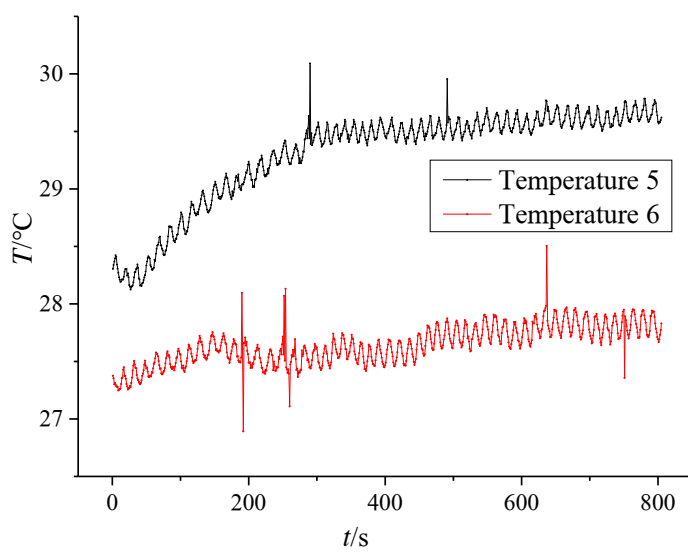

(a)

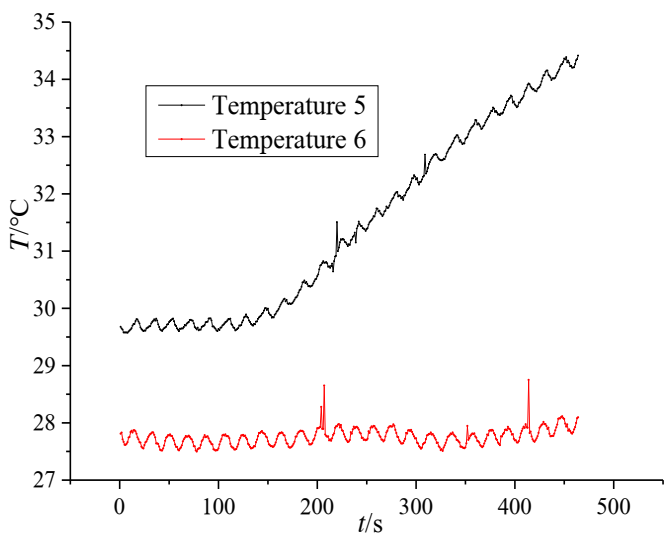

(b)

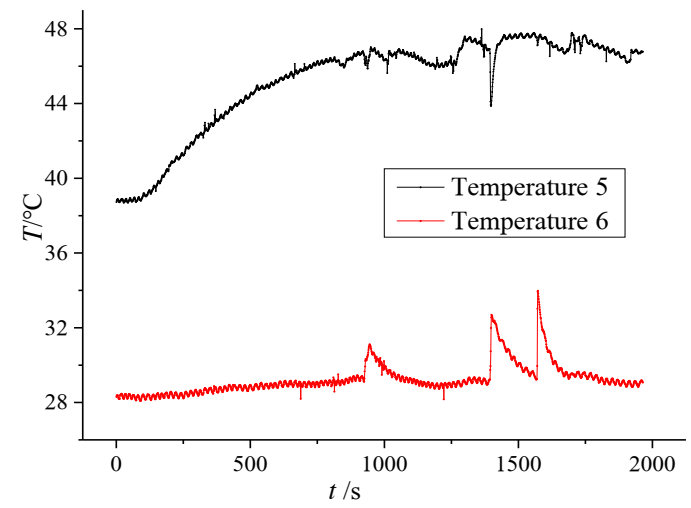

(c) 


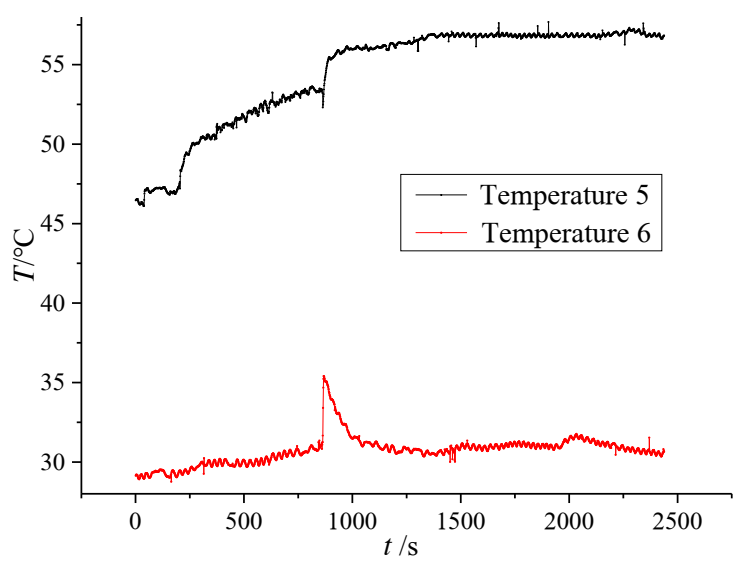

(d)

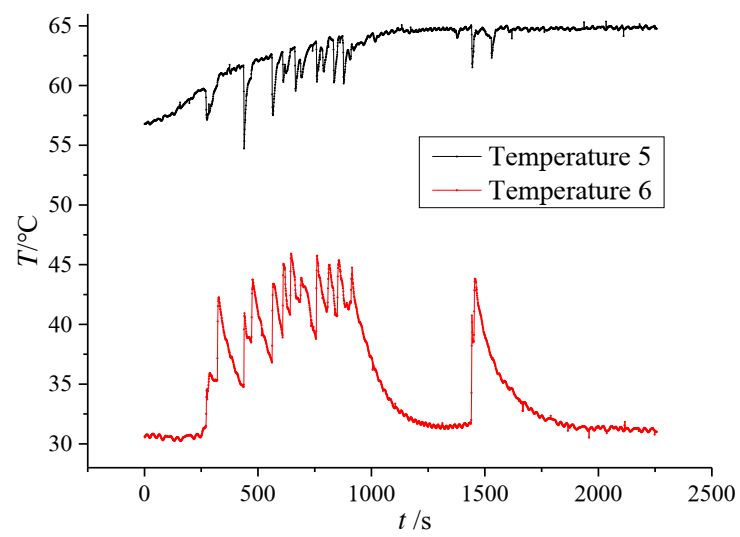

(e)

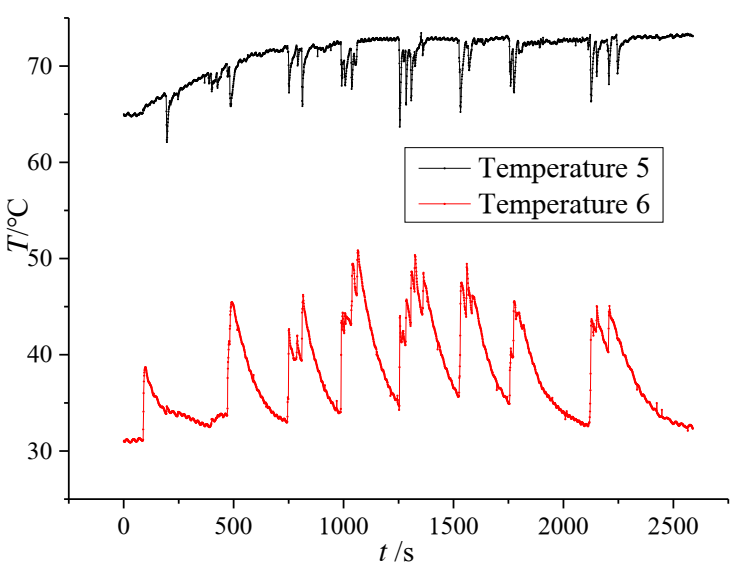

(f)

Fig. 3. Variation of wall temperature of pulsating heat pipe with time at $30^{\circ} \mathrm{C} \sim 80^{\circ} \mathrm{C}$

From the six figures in Fig.3, it can be concluded that the abscissa is the heating time and the ordinate is the temperature. In the experiment, the water in the thermostatic waterbath is heated from $27^{\circ} \mathrm{C}$. The gasliquid pulsating heat pipe heat exchanger starts to operate at $45^{\circ} \mathrm{C}$. When the temperature of the heat source reaches $60^{\circ} \mathrm{C}$, that is to say, when (d) diagram reaches a stable operation state, the best working temperature is $50^{\circ} \mathrm{C} \sim 60^{\circ} \mathrm{C}$. The above situation is the experimental results of pulsating heat pipe under $60 \%$ liquid filling rate and specific cold source environment.

When the heating temperature is $30^{\circ} \mathrm{C}$, there is no oscillation in the condenser and heating sections. This is because the temperature of heating section is not high and the pulsating heat pipe is not started. At this time, the heat transfer process of pulsating heat pipe mainly depends on the heat conduction of copper tube in pulsating heat pipe.

When the heating temperature is $40^{\circ} \mathrm{C}$, the temperature curves of heating and condenser sections occasionally oscillate in a large range in a short time. This phenomenon can be explained in the condenser section as follows: at this time, there are bubbles in the working medium in the heating section. When the working medium carrying bubbles reaches the condenser section, due to the good Condensation effect, the working medium of bubbles will release the latent heat of vaporization after being condensed in the condenser section, so that the wall temperature will suddenly rise; At the heating section, it can be explained as follows: when the working medium is heated to generate bubbles, due to the absorption of the latent heat of vaporization, it will conduct the wall temperature of the heating section is decreased instantaneously. At this time, the temperature difference between the hot and cold end of the whole pulsating heat pipe is still small, the pulsating heat pipe oscillates locally, and the whole pulsating heat pipe is still not started.

When the heating temperature is $50^{\circ} \mathrm{C}$, the instantaneous change of temperature is more frequent than before, and the oscillation of working medium in the tube is also more violent than that at $40^{\circ} \mathrm{C}$. It can be seen that the temperature curve has obvious instantaneous fluctuation from $45^{\circ} \mathrm{C}$, indicating that the gas-liquid pulsating heat pipe heat exchanger starts to start at about $45^{\circ} \mathrm{C}$, and the pulsating heat pipe begins to oscillate.

When the heating temperature is $60^{\circ} \mathrm{C}$, there is an intermittent and violent oscillation in the pulsating heat pipe heat exchanger. This is because the pressure in the heating section increases gradually due to the increase of temperature, and the pulse power of the pulsating heat pipe to the upper working medium increases, so that the circulation is accelerated and the heat transfer of pulsating heat pipe is accelerated; and with the increase of heating temperature, the steam quantity in the heating section is gradually increased, at the same time, the sensible heat and latent heat carried by the working medium in the pipe increases, and the overall heat transfer performance of pulsating heat pipe is enhanced ${ }^{[5}$ $\sim 8]$.

When the heating temperature reaches $80^{\circ} \mathrm{C}$, the boiling point is $100^{\circ} \mathrm{C}$ because the heat source medium used in the experiment is water. In order to avoid the boiling phenomenon in the thermostatic waterbath and pulsating heat pipe heat exchanger water tank. Therefore, when the heating temperature reaches $80^{\circ} \mathrm{C}$, the heating is not continued.

\subsection{Heat transfer analysis of pulsating heat pipe heat exchanger}

In the experimental setup, type $\mathrm{K}$ thermocouples are installed in the wind inlet, wind outlet, water inlet and water outlet. The experimental data are collected by data 
acquisition unit, and the heat release of water and the heat absorption of wind are drawn by Origin software when the heating temperature is different.

(1) Heat release of water $Q_{1}$ :

$$
Q_{1}=c_{p 1} q_{m 1} \Delta t_{1}
$$

In formula,

$c_{p 1}$ - specific heat of water at constant pressure, $\mathrm{kJ} /$ $(\mathrm{kg} \cdot \mathrm{K})$;

$\boldsymbol{q}_{\boldsymbol{m} \mathbf{1}}$ - mass flow of water, $\mathrm{kg} / \mathrm{S}$;

$\Delta t_{1}$ - temperature difference between inlet and outlet of water, ${ }^{\circ} \mathrm{C}$.

(2) Heat absorption of wind $\boldsymbol{Q}_{2}$ :

$$
Q_{2}=c_{p 2} q_{m 2} \Delta t_{2}
$$

In formula,

$c_{p 2}-$ specific heat of wind at constant pressure, $\mathrm{kJ} /(\mathrm{kg} \cdot \mathrm{K})$;

$\boldsymbol{q}_{\boldsymbol{m} \mathbf{2}}$ - mass flow of wind, $\mathrm{kg} / \mathrm{S}$;

$\Delta t_{2}$ - temperature difference between inlet and outlet of wind,${ }^{\circ} \mathrm{C}$.

During the experiment, the flow of water the inlet and outlet is controlled at $50 \mathrm{~L} / \mathrm{h}$ by the flow controller, and the volume flow of the corresponding wind is calculated by the wind volume of the fan at $18 \mathrm{cfm}$ (cubic inch per minute). The temperature difference between wind and water can be obtained in real time by data acquisition unit.

After calculation, After calculation, it can be concluded that at different heating temperatures, the realtime temperature difference between wind and water inlet and outlet is shown in Fig.4; After the different heating temperatures are stable, the average temperature difference between the inlet and outlet of wind and water, as well as the heat absorbed and released are as shown in Fig.5.

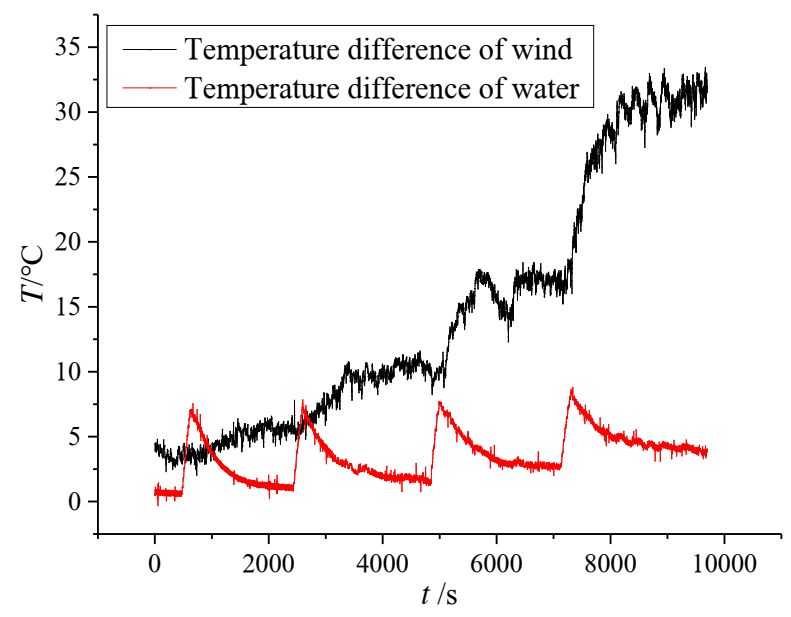

Fig.4. Temperature difference between inlet and outlet of wind and water at different heating temperatures
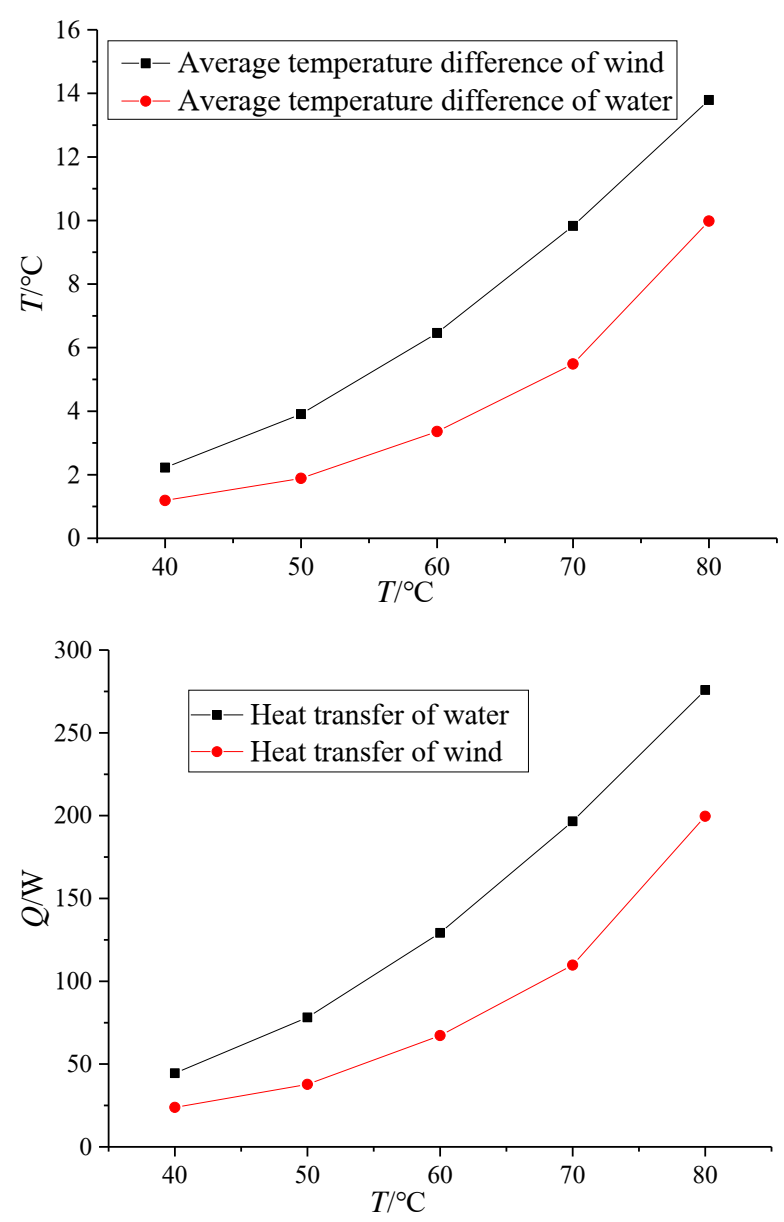

Fig. 5. Average temperature difference and heat transfer between wind and water at different temperatures

It can be concluded from Fig.4. that the temperature difference between the inlet and outlet of wind and water increases gradually with the increase of heating temperature. When the heating temperature reaches a certain value, the temperature difference between the inlet and outlet of the wind side is much larger than that of the water side. For further analysis, we extract the stable average temperature difference data and calculate the heat transfer, as shown in Fig.5: with the increase of heating temperature, the heat release of water and the heat absorption of wind are gradually increased. Moreover, with the increase of heating temperature, the heat release of water and the heat absorption of air increase gradually, especially when the heating temperature is $60^{\circ} \mathrm{C} \sim 80^{\circ} \mathrm{C}$, the increasing range of heat transfer reaches the maximum. The heat release of water is always greater than the heat absorption of wind, which shows that although the two data should be equal in theory, part of the heat release of water can be absorbed by the environment due to the heat loss in the actual operation process, so the heat absorbed by the wind side is less than the heat released by the water side.

The above situation also shows that with the increase of heating temperature, in the heat transfer process of pulsating heat pipe, in addition to the heat conduction of copper pipe and working medium, the latent heat of working medium in the pipe and the common heat transfer effect of latent heat and sensible heat are 
constantly emerging. That is to say, the working fluid in the pulsating heat pipe gradually changes from local oscillation to global oscillation, so that the stable working state of the oscillation cycle makes the heat transfer process of the pulsating heat pipe reach the best state.

\subsection{Analysis of equivalent heat conductivity of pulsating heat pipe}

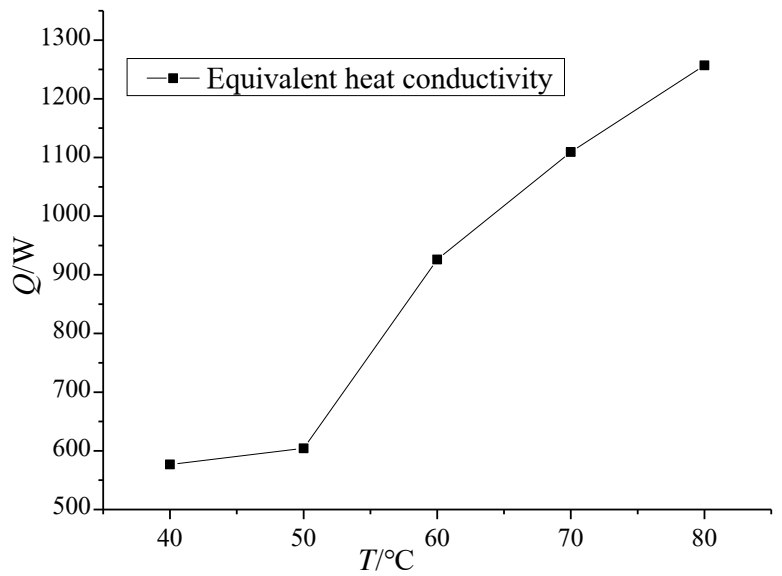

Fig.6. Change of equivalent heat conductivity of gas-liquid pulsating heat pipe heat exchanger with heating temperature

Fig.6. shows the equivalent heat conductivity of pulsating heat pipe at different temperatures from $40^{\circ} \mathrm{C}$ to $80^{\circ} \mathrm{C}$. Where, equivalent heat conductivity

$$
\lambda_{d}=\frac{Q_{2} L}{\left(T_{r}-T_{l}\right) A}
$$

In formula,

$Q_{2}$ - heat transfer, i.e. heat absorption of wind, W;

$\boldsymbol{L}$ - average distance between cold and hot end measuring points of pulsating heat pipe, $\mathrm{m}$;

$\boldsymbol{T}_{\boldsymbol{r}}$ and $\boldsymbol{T}_{\boldsymbol{l}}$ - the average temperature of the hot and cold pipe wall of the pulsating heat pipe, ${ }^{\circ} \mathrm{C}$;

$\boldsymbol{A}$ - total heat transfer area, $\mathrm{m}^{2}$.

It can be concluded from the figure that the equivalent heat conductivity of the pulsating heat pipe heat exchanger increases with the increase of heating temperature. Especially when the temperature is above $50^{\circ} \mathrm{C}$, the heat transfer performance of the pulsating heat pipe is improving because of the coexistence of sensible heat and latent heat.

After calculation, the equivalent heat conductivity $\lambda_{D}$ is $570 \mathrm{~W} /(\mathrm{m} \cdot \mathrm{K})$ at $40^{\circ} \mathrm{C}, 590 \mathrm{~W} /(\mathrm{m} \cdot \mathrm{K})$ at $50^{\circ} \mathrm{C}, 910$ $\mathrm{W} /(\mathrm{m} \cdot \mathrm{K})$ at $60^{\circ} \mathrm{C}, 1120 \mathrm{~W} /(\mathrm{m} \cdot \mathrm{K})$ at $70^{\circ} \mathrm{C}$ and 1260 $\mathrm{W} /(\mathrm{m} \cdot \mathrm{K})$ at $80^{\circ} \mathrm{C}$. The equivalent heat conductivity is much higher than that of copper tube at the same temperature. It shows that the gas-liquid pulsating heat pipe heat exchanger has good heat transfer capability.

\section{Conclusions}

(1) The experimental results show that the temperature has a great influence on the gas-liquid pulsating heat pipe.
In this experiment, the pulsating heat pipe starts at about $45^{\circ} \mathrm{C}$, and reaches the best operation state between $50^{\circ} \mathrm{C}$ and $60^{\circ} \mathrm{C}$.

(2) From the experimental results, the heat transfer capacity and equivalent heat conductivity of gas-liquid pulsating heat pipe are much higher than that of common copper pipe, so it has better heat transfer capacity.

(3) In this experiment, the maximum temperature of heat source is $80^{\circ} \mathrm{C}$. However, from the trend of heat transfer and equivalent heat conductivity of pulsating heat pipe changing with heating temperature, the experimental device of pulsating heat pipe heat exchanger still showed good performance for higher heat source temperature, that is, it is also suitable for higher heat source working temperature.

\section{Acknowledgment}

This work was supported by the science and technology development project of Jilin province (Grant numbers 20190303113SF), and industrial technology research and development project of Jilin province (2019C057-5).

\section{References}

1. AKACHI H. Structure of a heat pipe: US, 4921041[P/OL], (1990)

2. AKACHI H. Structure of micro-heat pipe: US, 5219020[P-OL], (1993)

3. AKACHI H. L-type heat sink: US, 5490558[P-OL], (1996)

4. AKACHI H. Looped capillary heat pipe: Japanese, Hei 6-97147[P-OL], (1994)

5. Yafang Han. Study on heat transfer characteristics of pulsating heat pipe and its heat exchanger[D]. Beijing University of Technology (2013)

6. Tianlun Lin, Hongmei Yang, Lihui Wu. Experimental study on the aftercooling recovery device of pulsating heat pipe for air conditioning [J]. Refrigeration and air conditioning, (2010, 10: 56-58)

7. Tianlun Lin, Hongmei Yang. Study on the application of aluminum ammonia heat pipe heat exchanger in air conditioning exhaust heat recovery [J]. Refrigeration and air conditioning, (2011, 11: 62-65)

8. Lihua Liu, Guangyu Zhang, Shouzhong Jiang. Experimental study on heat transfer performance of closed loop self-excited oscillating heat pipe with constant wall temperature $[\mathrm{J}]$. Fluid machinery, (2008, 36: 58-62) 